\title{
Associação entre os polimorfismos HaelII e Mspl do gene para o receptor alfa de estrogênio e densidade mamográfica em mulheres após a menopausa
}

\author{
Association between HaeIII and MspI polymorphisms of estrogen receptor alpha gene \\ and mammographic density in post-menopausal women
}

Eduardo Henrique de Moura Ramos ${ }^{1}$, Cláudio Kemp², Ismael Dale Cotrim Guerreiro da Silva ${ }^{3}$

\begin{abstract}
RESUMO
Objetivo: Avaliar a presença dos polimorfismos HaeIII e MspI do gene para o receptor de estrogênio alfa, bem como fatores clínicos e suas possíveis associações com a densidade mamográfica em mulheres após a menopausa. Métodos: Foram avaliadas 115 mulheres após a menopausa, não usuárias de terapia hormonal e sem lesão mamária clínica ou mamograficamente identificada. A densidade mamográfica foi determinada por três observadores independentes, tomando-se como base a classificação dos padrões mamográficos do ACR-BIRADS ${ }^{\circledR}, 2003$ (duas avaliações subjetivas e uma computadorizada - Adobe Photoshop ${ }^{\circledR}$ 7.0). Amostras de raspado bucal foram obtidas para extração de DNA e em seguida foi realizada uma PCR-RFLP (Polymerase Chain Reation - Restriction Fragment Length Polymorphism) para análise de polimorfismos presentes no íntron 1 e éxon 1 do gene do RE $\alpha$ (HaeIII e MspI). Resultados: O polimorfismo HaeIII foi encontrado em $43(37,4 \%)$ das 115 mulheres, ao passo que o MspI estava presente em $96(83,5 \%)$ das mesmas. Houve alto grau de concordância entre os três observadores na determinação da densidade mamográfica. Trinta e quatro $(29,6 \%)$ mulheres tinham mamas densas, e 81 (70,4\%), mamas lipossubstituídas. Conclusão: Não houve associação entre o polimorfismo HaeIII do gene para o receptor de estrogênio alfa e densidade mamográfica (Fisher $=0,712$ ). Houve associação próxima à significância estatística entre o polimorfismo $M s p I$ e densidade (Fisher =0,098). Idade, paridade e índice de massa corporal mostraram-se associados com densidade mamográfica.
\end{abstract}

PALAVRAS-CHAVE: Receptores estrogênicos; Polimorfismo genético; Mamografia; Neoplasias mamárias; Pós menopausa

\section{ABSTRACT}

Purpose: To assess the presence of estrogen receptor gene polymorphisms HaeIII and MspI as well as clinical factors, and their possible associations with high mammographic density in post-menopausal women. Methods: One hundred and fifteen post-menopausal women, not in use of hormonal therapy and without clinical or mammographic lesions were evaluated. Three independent observers have determined the mammographic density pattern based on the ACR-BIRADS ${ }^{\circledR}$ 2003 (two subjective and one objective evaluations - Adobe Photoshop 7.0 software). Oral swabs (Cytobrush) were obtained to extract DNA and the polymerase chain reaction - restriction fragment length polymorphism) was performed to assess the presence of polymorphisms in intron 1 and exon 1 from estrogen receptor gene (HaeIII and MspI). Results: The HaeIII polymorphism was found in $43(37.4 \%)$ of the 115 women, while MspI was found in $96(83.5 \%)$ of them. There was a good agreement among determinations of the three observers with regard to mammographic density. Thirty-four (29.6\%) women had dense breasts and eighty-one (70.4\%) had non-dense breasts. Conclusion: The estrogen receptor gene polymorphism Haelll showed no association with mammographic density (Fisher $=0.712$ ), while the association between estrogen receptor gene polymorphism Mspl and mammographic density was near significance $($ Fisher $=0.098)$. The associations among age, parity and body mass index revealed statistical significance.

KEYWORDS: Receptors, estrogen; Polymorphism, genetic; Mammography; Breast neoplasms; Postmenopause

Apoio financeiro: Fundação de Apoio à Pesquisa do Estado de São Paulo - FAPESP - São Paulo (SP), Brasil. Processo 03/04533-1.

Setor de Diagnóstico, Disciplina de Mastologia, Escola Paulista de Medicina, Universidade Federal de São Paulo - UNIFESP - São Paulo (SP), Brasil.

1 Pós-graduando do Setor de Diagnóstico, Disciplina de Mastologia, Escola Paulista de Medicina, Universidade Federal de São Paulo - UNIFESP - São Paulo (SP), Brasil.

2 Professor Adjunto do Departamento de Ginecologia e Chefe do Setor de Diagnóstico, Disciplina de Mastologia, Escola Paulista de Medicina, Universidade Federal de São Paulo - UNIFESP - São Paulo (SP), Brasil.

3 Professor Adjunto e Coordenador do Laboratório de Ginecologia Molecular, Departamento de Ginecologia, Escola Paulista de Medicina, Universidade Federal de São Paulo - UNIFESP - São Paulo (SP), Brasil.

Correspondência: Eduardo Henrique de Moura Ramos

Av. Carinás, 408 - Moema - 04086-010 - São Paulo-SP - e-mail: eh_moura@yahoo.com.br

Recebido em: 20/07/2006 Aceito com modificações em: 18/09/2006 


\section{Introdução}

A expressão radiológica da variação na composição mamária, determinada pelas quantidades relativas dos tecidos adiposo, conjuntivo e epitelial é conhecida como padrão mamográfico. Há três formas de classificá-lo, utilizando os critérios de Wolfe, de Làzló Tabár e do ACR-BIRADS ${ }^{\circledR}$ (American College of Radiology - Breast Imaging Reporting and Data System).

Wolfe $(1976)^{1}$ calculava as densidades mamográficas com a ajuda de um planímetro manual, descrevendo quatro padrões: padrão N1 (N: "normal") - mamas eminentemente adiposas; padrão P1 (P: proeminent), mamas constituídas predominantemente por tecido adiposo, mas com áreas densas de predomínio ductal ocupando até $25 \%$ da área total; padrão P2, mamas com áreas densas de predomínio ductal ocupando $25 \%$ ou mais da área total, e padrão DY (DY: dysplasia), mamas com extensas áreas densas nodulares. Mulheres com mamas de aspecto P2 ou DY teriam probabilidade 37 vezes maior para desenvolver câncer de mama do que aquelas com padrão $\mathrm{N} 1$ ou $\mathrm{P}^{1}{ }^{1}$.

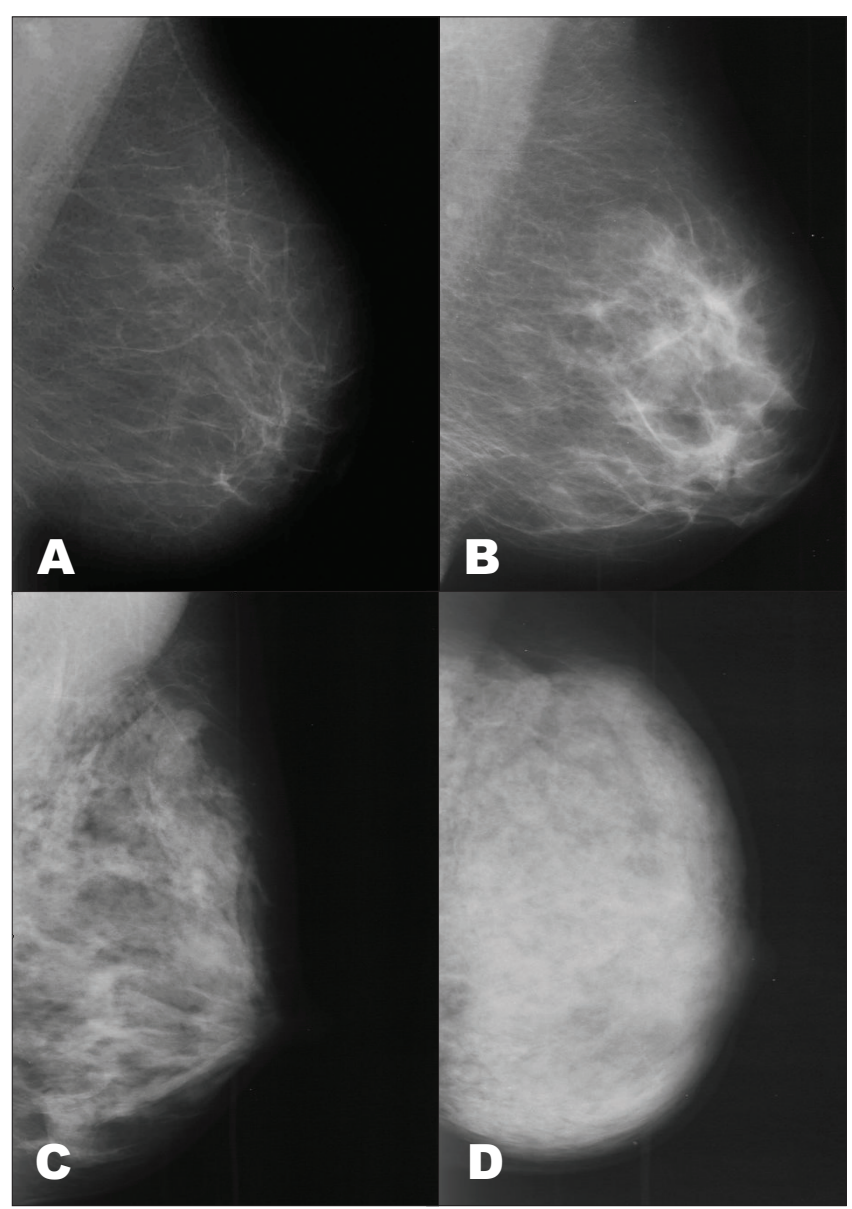

Figura 1 - Incidências oblíquas mediolaterais esquerdas representando os padrões mamográficos do ACR-BIRADS ${ }^{\circledR}$ : a) Padrão 1 b) Padrão 2; c) Padrão 3; e d) Padrão 4.
A comparação de caracteres anatômicos com mamográficos levou Làzló Tabár a criar um sistema de classificação contendo cinco padrões parenquimais radiológicos. Em cada um deles a imagem representa uma mistura de quatro componentes estruturais: densidades nodulares (lóbulos); densidades lineares (estruturas fibrosas, vasos sanguíneos e ductos); densidades homogêneas fibrosas (tecido fibroso), e áreas radiotransparentes (tecido adiposo). Os padrões I, II e III seriam involutivos (haveria processo de lipossubstituição) e os padrões IV e V seriam imutáveis (não haveria lipossubstituição) ${ }^{2}$.

Em 2003 o Colégio Americano de Radiologia atualizou sua classificação, correlacionando a quantidade de densidades parenquimatosas com a sensibilidade do exame mamográfico, e não mais com o maior ou menor risco para câncer de mama, inicialmente descrito por Wolfe. Também são descritos quatro padrões: mamas lipossubstituídas (menos de 25\% de tecido fibroglandular); mamas parcialmente lipossubstituídas (25 a 50\% de tecido fibroglandular); mamas heterogeneamente densas (50 a $75 \%$ de tecido fibroglandular), e mamas extremamente densas (mais de $75 \%$ de tecido fibroglandular) ${ }^{3}$ (Figura 1)

O padrão mamográfico depende da distribuição dos elementos estruturais mamários (ductos, alvéolos, estruturas fibrosas e adiposas), que sofrem influências genéticas e ambientais. À medida que a quantidade desses elementos se modifica com a idade, estimulada pela ação dos hormônios sexuais, fornece aspectos da imagem compativeis com cada período ${ }^{4}$.

Com a menopausa, ocorre involução no epitélio glandular e no tecido acinolobular. Tornam-se atróficos e são substituídos por células adiposas. Essa involução é progressiva, porém não uniforme, pois algumas mulheres mantêm um padrão mamográfico denso, traduzindo-se em predomínio de tecido fibroglandular ${ }^{5}$. Essa densidade radiológica elevada assume importância, pois é considerada por alguns como um dos fatores de risco independentes para câncer de mama ${ }^{1,5-8}$.

A base genética que envolve a sintese de proteínas responsáveis pela manutenção dos niveis hormonais foi recentemente reconhecida como um importante fator de risco para câncer de mama ${ }^{9}$. Tem-se tornado mais claro que a herança genética, agindo por meio de polimorfismos, apresenta papel relevante nessa gênese. Pode-se definir polimorfismo como uma variação genética que ocorre normalmente na população geral, com freqüência $>1 \%{ }^{10}$. Os polimorfismos podem contribuir para o desenvolvimento de várias doenças, sobretudo aquelas em tecidos dependentes de hormônio,

Rev Bras Ginecol Obstet. 2006; 28(10): 581-89. 
e também explicar as variações individuais na densidade mamográfica ${ }^{11,12}$.

As tentativas de encontrar bases genéticas para a densidade mamográfica são recentes. A hipótese de que a transmissão de um gene dominante influenciava a densidade mamográfica resultou na análise de 1.370 mamografias em 258 famílias independentes, observando-se uma associação significante entre irmãs. Acreditava-se que um gene autossômico dominante influenciava a densidade mamária. Entretanto, hipóteses envolvendo herança de outros genes (recessivos) não deveriam ser desprezadas ${ }^{13}$.

Os polimorfismos em genes que regulam a biossíntese e o metabolismo de hormônios esteróides também foram analisados para explicar as variações nos padrões mamográficos. Esses polimorfismos poderiam representar biomarcadores com longo tempo de exposição a hormônios endógenos e potenciais fatores de risco para câncer de mama. A densidade mamária poderia ser hereditária, pelo menos em parte, e múltiplos genes estariam envolvidos ${ }^{14}$.

A presença de polimorfismos do receptor para estrogênio tem sido relacionada com o risco para câncer de mama. Observou-se maior densidade mamográfica em mulheres com um ou dois alelos polimórficos. Dessa forma, sugeriu-se que polimorfismos do receptor para estrogênio, presentes naquelas com mamas densas, afetariam o risco para câncer de mama ${ }^{15}$.

Se fatores genéticos (que formam a base da densidade mamária) aumentam o risco para câncer de mama, então a densidade mamográfica deveria estar associada à história familiar desse câncer. Mamografias de 6.146 mulheres foram analisadas, encontrando-se associação significante entre densidade mamária aumentada e história de parente em primeiro grau com câncer de mama. Dessa forma, concluiu-se que fatores genéticos relacionados com a densidade mamária estariam associados com história familiar de câncer de mama ${ }^{16}$.

Um dos primeiros estudos a demonstrar evidente relação entre um polimorfismo genético e densidade mamográfica foi desenvolvido por Lai et al. ${ }^{17}$. Sabendo-se que um alto nivel circulante de fator de crescimento insulina-simile 1 (IGF-1) e baixo nivel de IGF ligado à proteína 3 (IGFBP-3) tinham sido associados ao aumento na densidade em mulheres antes da menopausa, tentaram determinar se variações polimórficas nos genes de IGF-I e IGFBP-3 estavam relacionadas com esse padrão de mama. Não encontraram associação entre os niveis séricos de IGF-I e IGFBP-3 e densidade. Porém, havia uma associação positiva entre níveis séricos de IGFBP-3 e o número de alelos "A", encontrados no locus polimórfico na região promotora do gene IGFBP-3. Aquelas com dois alelos "A" tinham probabilidade cinco vezes maior de ter mama densa em comparação com as que não apresentavam o referido alelo. Uma associação menos significante foi encontrada entre níveis séricos de IGFBP-3 e o alelo "A" em mulheres após a menopausa. Já o polimorfismo no gene do IGF-I não parecia estar fortemente associado com a densidade mamária.

Sabendo-se que a terapia hormonal (TH) aumenta a densidade mamográfica, foi investigado se o seu efeito poderia ser modificado por polimorfismos no receptor para estrogênio (RE) e progesterona. Uma diferença significante de aumento na densidade mamográfica entre usuárias e não usuárias de TH foi encontrada em mulheres com polimorfismos do RE. Esses polimorfismos poderiam torná-las mais susceptiveis aos efeitos da $\mathrm{TH}$, como se verificou nas mamografias ${ }^{18}$.

Dessa forma, tentando encontrar um possivel fator genético relacionado com a persistência do padrão mamográfico denso observado em algumas mulheres após a menopausa, este estudo procurou avaliar uma eventual associação entre presença dos polimorfismos HaeIII e MspI do gene para o receptor de estrogênio alfa e densidade mamográfica, e também a associação dessa última com fatores clínicos.

\section{Métodos}

Foram incluidas prospectivamente 115 mulheres atendidas no Setor de Climatério, que eram enviadas ao Setor de Diagnóstico (Disciplina de Mastologia, Departamento de Ginecologia, Escola Paulista de Medicina - Universidade Federal de São Paulo, EPM-UNIFESP), entre janeiro e março de 2005. O estudo foi previamente aprovado pela Comissão de Ética em Pesquisa da EPM-UNIFESP.

Essas mulheres caracterizavam-se por apresentar amenorréia por tempo $\geq \mathrm{um}$ ano, e por apresentarem dosagem sérica de $\mathrm{FSH}>30 \mathrm{UI} / \mathrm{ml}$ e de estradiol $<50 \mathrm{pg} / \mathrm{ml}$. Não faziam uso de qualquer medicação hormonal e não tinham doença endócrina, hepática ou renal que pudessem alterar o metabolismo estrogênico. Todas tinham mamografia normal (categorias 1 ou 2 do ACR-BIRADS ${ }^{\circledR}$ ).

\section{Determinação da Densidade Mamográfica}

Todas foram submetidas a mamografia bilateral e ultra-sonografia mamária, quando necessário. A densidade mamográfica foi determinada por três observadores independentes. Dois deles (observadores 1 e 2) classificaram as mamografias subjetivamente, tomando como base os padrões mamográficos do ACR-BIRADS ${ }^{\circledR}$, 2003. A terceira 
determinação, computadorizada (observador 3), foi realizada como se segue: por convenção, a imagem da incidência oblíqua médio-lateral esquerda foi digitalizada e capturada pelo scanner CX312.T (Radiographic Digital Imaging, Compton, CA, USA); as imagens eram armazenadas em Compact Disc (CD) e posteriormente utilizadas no programa Adobe Photoshop ${ }^{\circledR}$, v. 7.0. Com esse programa, inicialmente empregava-se a ferramenta magic wand tool, selecionando toda a mama (com cuidado para excluir o músculo peitoral), encontrando assim um valor numérico que correspondia à quantidade pixels da área mamária geral. A seguir, selecionavase com a mesma ferramenta a área mamária mais densa, obtendo-se assim a quantidade de pixels dessa região; finalmente, para determinar um valor percentual de tecido fibroglandular, estabelecia-se uma relação entre os dois valores iniciais, segundo a fórmula: densidade mamográfica $\left(\right.$ Photoshop $\left.^{\circledR}\right)=$ área densa (pixels) x 100/área total (pixels).

Os valores percentuais de áreas densas assim obtidos eram comparados com as classificações subjetivas determinadas pelos dois outros observadores, para avaliar o grau de concordância entre eles. A medida adotada foi a estatística kappa ${ }^{19}$. Para medidas com máximo grau de concordância ela assume o valor 1 e para ausência de concordância assume o valor 0 .

Como havia poucas pacientes com mamas extremamente densas, as 115 mulheres foram classificadas pelos três observadores em dois grupos principais de densidades mamográficas: grupo A (aquelas com até $50 \%$ de tecido fibroglandular, mamas lipossubstituídas) e grupo B (aquelas com mais de $50 \%$ de tecido fibroglandular, mamas densas). Por ser um método exato e desprovido de tendência, utilizamos como valores de referência as densidades obtidas pelo observador 3 .

\section{Coleta de material biológico}

As amostras com raspado bucal foram obtidas através de escova do tipo cytobrush, friccionadas contra a mucosa de revestimento bucal. Posteriormente, foram conservadas em $-80^{\circ} \mathrm{C}$ até posterior extração do DNA genômico.

\section{Extração de DNA do raspado bucal}

Foi realizada segundo o protocolo do Kit GFX ${ }^{\circledR}$ da Amersham-Pharmacia para células bucais. Resumidamente, o material celular (esfregaço bucal) foi centrifugado. Ao concentrado celular foram adicionados $500 \mu 1$ de solução de extração, agitando-se até que fosse dissolvido. Essa etapa foi seguida de centrifugação a $14.000 \mathrm{rpm} / \mathrm{min}$ (Eppendorf, modelo $5804 \mathrm{R}$ ) para separar restos celulares do sobrenadante que foi, nesse momento, colocado na coluna de filtração. Após nova centrifugação a $14.000 \mathrm{rpm} / \mathrm{min}$, uma nova aliquota de $500 \mu 1$ da solução de extração foi colocada na coluna, com posterior centrifugação a $14.000 \mathrm{rpm} / \mathrm{min}$. Seguiu-se então a adição de $500 \mu 1$ de solução limpadora, com nova centrifugação a $14.000 \mathrm{rpm}$ (3 $\mathrm{min})$. Nesse momento, adicionaram-se à coluna $70 \mu 1$ de água milliQ autoclavada, pré-aquecida a $70^{\circ} \mathrm{C}$, seguida de centrifugação a $14.000 \mathrm{rpm} / \mathrm{min}$, coletando-se o eluído em tubo Eppendorf; o DNA então obtido achava-se pronto para ser utilizado na reação em cadeia da polimerase (polymerase chain reaction, PCR). A quantificação do DNA foi feita por meio de espectrofotometria, com comprimento de onda $=260 \mathrm{~nm}$ (espectrofotômetro Spectronic, modelo Genesys 5).

\section{Reação em cadeia de polimerase para o intron 1 do gene do RE $\alpha$}

Nas reações foram usados $200 \mathrm{ng}$ do DNA genômico em um volume final de $25 \mu$ de reação contendo: $5 \mathrm{pmol} / \mu 1$ de cada primer sense (5'-cat cta ctc cta tgt ctg gt-3') e anti-sense (5'-cgt gta gac tga agg gca t-3'), $10 \mu 1$ de mix Promega (50 U/ml de Taq DNA polimerase, $\mathrm{pH} 8,5,400 \mu \mathrm{M}$ de dATP, $400 \mu \mathrm{M}$ de dCTP, $400 \mu \mathrm{M}$ de dGTP, $400 \mu \mathrm{M}$ de dTTP e $3 \mathrm{mM}$ de $\mathrm{MgCl}_{2}$; Promega ${ }^{\circledR}$ Corporation, Madison, WI, USA) e $12 \mu \mathrm{H}_{2} \mathrm{O}$ de nuclease-free Promega, que foram submetidos ao termociclador (GeneAmp PCR System 9700, Applied Biosystems) por 40 ciclos, onde a primeira etapa de desnaturação foi de $94^{\circ} \mathrm{C}$ por 30 segundos, anelamento a $54^{\circ} \mathrm{C}$ por 45 segundos e polimerização a $72^{\circ} \mathrm{C}$ por 45 segundos. A eletroforese foi feita em gel de agarose a $2 \%$ / brometo de etídio e o padrão obtido nesta reação foi de 227 pb.

PCR-RFLP (Restriction Fragment Length Polymorphism)

Para análise do polimorfismo presente no intron 1 do gene do REa (receptor de estrogênio alfa), os produtos da PCR foram incubados em um volume de $10 \mu \mathrm{l}$ (a $37^{\circ} \mathrm{C}$, por $4 \mathrm{~h}$ ), contendo 3 unidades da enzima HaeIII (Invitrogen Life Technologies, Carlsbad, CA, USA) e $8 \mu 1$ do produto da PCR. A enzima de restrição HaeIII reconhecia o seguinte trecho da seqüência da PCR amplificado para este trecho do gene REa: 5'-GG $\downarrow$ CC 3'/3'-CC $\uparrow G G-3$ '.

\section{Reação em cadeia de polimerase para o éxon 1 do gene do RE $\alpha$}

Nas reações foram usados $200 \mathrm{ng}$ do DNA genômico em um volume final de $25 \mu$ de reação 
contendo: $5 \mathrm{pmol} / \mu \mathrm{l}$ de cada primer sense (5'-atg cgc tgc gtc gcc tct aa-3') e anti-sense (5'-ctg cag gaa agg cga cag ct-3'), $10 \mu 1$ de mix Promega (50 U/ml de Taq DNA polimerase, $\mathrm{pH} 8,5,400 \mu \mathrm{M}$ de dATP, $400 \mu \mathrm{M}$ de dCTP, $400 \mu \mathrm{M}$ de dGTP, $400 \mu \mathrm{M}$ de dTTP e $3 \mathrm{mM}$ de $\mathrm{MgCl}_{2}$; Promega ${ }^{\circledR}$ Coorporation, Madison, WI, USA) e $12 \mu 1 \mathrm{H}_{2} \mathrm{O}$ de nuclease-free Promega, que foram submetidos ao termociclador (GeneAmp PCR System 9700, Applied Biosystems) por 40 ciclos, onde a primeira etapa de desnaturação foi de $94^{\circ} \mathrm{C}$ por 30 segundos, anelamento $\left(56^{\circ} \mathrm{C}, 45 \mathrm{~s}\right)$ e polimerização $\left(72^{\circ} \mathrm{C}, 90 \mathrm{~s}\right)$. A eletroforese foi feita em gel de agarose a $2 \% /$ brometo de etídio e o padrão obtido nesta reação foi de $479 \mathrm{pb}$.

\section{PCR-RFLP}

Para análise do polimorfismo presente no éxon 1 do gene para o REa, os produtos da PCR foram incubados em um volume de $10 \mu 1$ a $37^{\circ} \mathrm{C}$ por $4 \mathrm{~h}$, contendo: 3 unidades da enzima MspI (Fermentas International Inc., Ontario, Canada), 0,1 $\mu \mathrm{l}$ BSA (bovine serum albumin) e $8 \mu 1$ do produto da PCR. A enzima de restrição $M s p I$ reconhecia o seguinte trecho na seqüência do PCR amplificado para este trecho do gene REa: 5'...C $\downarrow$ CGG...3' / 3'...GGC $\uparrow C . . .3$ '.

As variáveis genéticas (polimorfismos HaeIII e $M s p I$ ) bem como as clínicas (idade, menarca, menopausa, paridade, IMC - índice de massa corporal (IMC), amamentação e tabagismo) foram analisadas, tentando-se encontrar os fatores que estariam associados com a densidade mamográfica.

A comparação entre as médias dessas variáveis quantitativas nos dois grupos de densidades mamográficas (A e B) foi realizada com o teste $t$ de Student para duas amostras independentes, após o teste para igualdade de variâncias de Levene ${ }^{20}$.

Estudamos a associação entre variáveis categóricas por meio do teste de associação de quiquadrado. Quando a freqüência esperada foi $<5$, utilizamos o teste exato de Fisher ${ }^{19}$.

Foi utilizado um nivel de significância de 5\% para conclusão em todos os testes.

\section{Resultados}

As características clinicas das 115 mulheres encontram-se resumidas nas Tabelas 1 e 2 .

Encontramos três situações distintas, dependendo da presença ou não dos polimorfismos em um dos alelos. Chamávamos de: selvagem, quando não havia alelo polimórfico; heterozigoto, quando havia um polimórfico, e mutado, quando os dois alelos eram polimórficos (Figura 2).
O polimorfismo HaeIII foi encontrado em 43 $(37,4 \%)$ das 115 mulheres, ao passo que o MspI, estava presente em $96(83,5 \%)$ das 115 mulheres (Figura 2).

O grau de concordância na determinação da densidade mamográfica entre os observadores, segundo o método estatístico de kappa, foi o seguinte: 0,919 (observadores 1 e 3); 0,821 (observadores 1 e 2) e 0,769 (observadores 2 e 3) (Tabela 3).

A associação entre presença do polimorfismo HaeIII do gene para o receptor de estrogênio alfa com os grupos A e B de densidades mamográficas não se mostrou significante (Fisher $=0,712$ ) (Tabela 4), assim como a associação entre presença do polimorfismo MspI com os grupos A e B de densidades mamográficas (Fisher = 0,098) (Tabela 4).

Houve associação positiva entre densidade mamográfica e as variáveis idade, paridade e IMC.

Tabela 1 - Caracterização clínica de mulheres $(n=115)$ após menopausa, incluídas no estudo.

\begin{tabular}{lccc}
\hline Variáveis & Médias & Medianas & Desvios padrão \\
\hline Idade (anos) & 51,9 & 52 & 4,3 \\
Menarca (anos) & 13,4 & 13 & 1,6 \\
Menopausa (anos) & 48,5 & 49 & 4,3 \\
Paridade & 3 & 3 & 1,4 \\
(n ${ }^{0}$ de filhos) & & 26,9 & 4,3 \\
IMC & 27,2 & & \\
\hline
\end{tabular}

IMC: Índice de Massa Corporal.

Tabela 2 - Caracterização clínica de mulheres $(n=115)$ após a menopausa.

\begin{tabular}{lccc}
\hline Variáveis & Sim & Não & Total \\
\hline Amamentação* & $103(89,6 \%)$ & $12(10,4 \%)$ & $115(100 \%)$ \\
Tabagismo** $^{* *}$ & $29(25,2 \%)$ & $86(74,8 \%)$ & $115(100 \%)$ \\
\hline
\end{tabular}

*Até 6 meses; ${ }^{* *}$ Consumo de até 20 cigarros/dia.

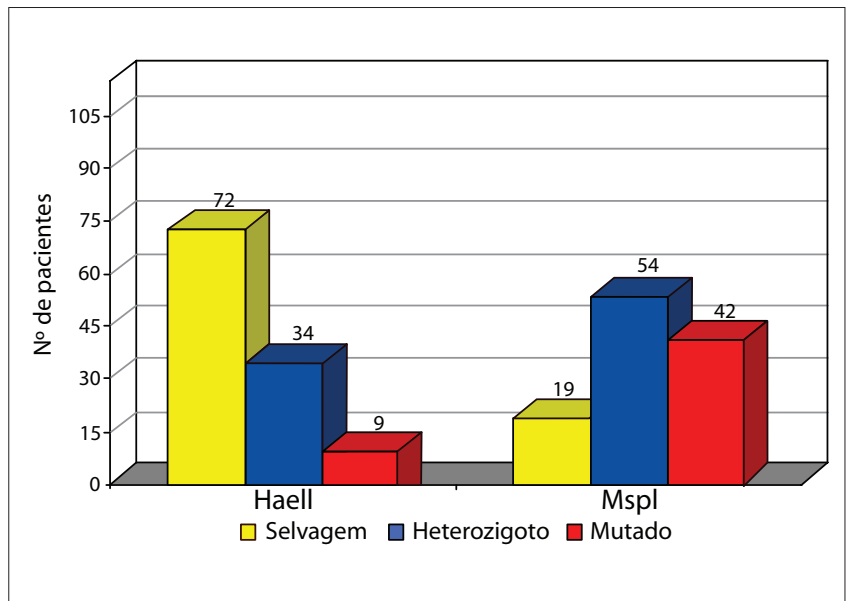

Figura 2 - Distribuição dos polimorfismos Haelll e Mspl do gene para o receptor de estrogênio alfa, segundo as variantes selvagem, heterozigoto e mutado, encontradas em pacientes $(n=115)$ após a menopausa. 
Tabela 3 - Distribuição das densidades mamográficas para mulheres $(n=115)$ após a menopausa, e grau de concordância entre observadores para determinação das densidades.

\begin{tabular}{lrcrcrc}
\hline & \multicolumn{5}{c}{ Observadores $^{* *}$} \\
Densidades* & \multicolumn{2}{c}{1} & \multicolumn{2}{c}{2} & \multicolumn{2}{c}{3} \\
\cline { 2 - 7 } & $\mathbf{n}$ & $(\%)$ & $\mathbf{n}$ & $(\%)$ & \multicolumn{1}{c}{$\mathbf{c}$} & $(\%)$ \\
\hline D1 & 26 & $(22,6)$ & 32 & $(27,8)$ & 25 & $(21,7)$ \\
D2 & 55 & $(47,8)$ & 48 & $(41,7)$ & 56 & $(48,7)$ \\
D3 & 27 & $(23,5)$ & 27 & $(23,5)$ & 28 & $(24,4)$ \\
D4 & 7 & $(6,1)$ & 8 & $(7)$ & 6 & $(5,2)$ \\
Total & 115 & $(100)$ & 115 & $(100)$ & 115 & $(100)$ \\
\hline
\end{tabular}

${ }^{*}$ De acordo com ACR-BIRADS ${ }^{\circledR}$; ${ }^{*}$ Observadores 1 e 2 (avaliação subjetiva), observador 3 (avaliação objetiva). Graus de concordância entre observadores: 1 e 3 (kappa = 0,919); 1 e 2 (kappa =0,821); 2 e 3 (kappa =0,769).

Tabela 4 - Distribuição dos polimorfismos Haelll e Mspl do gene para o receptor de estrogênio alfa encontrados em 115 pacientes após a menopausa de acordo com os grupos de densidade mamográfica determinados pelo observador 3 .

\begin{tabular}{|c|c|c|c|c|c|}
\hline \multirow{3}{*}{ Polimorfismos } & \multirow[b]{3}{*}{ Fisher } & \multicolumn{4}{|c|}{ Densidades } \\
\hline & & $\mathrm{n}$ & $\%$ & $\mathrm{n}$ & $\%$ \\
\hline & & \multicolumn{2}{|c|}{$\begin{array}{c}\text { Mamas } \\
\text { lipossubstituídas* }\end{array}$} & \multicolumn{2}{|c|}{ Mamas densas* } \\
\hline Haelll & 0,712 & & & & \\
\hline Selvagem & & 51 & $63 \%$ & 21 & $61,7 \%$ \\
\hline Heterozigoto & & 23 & $28,4 \%$ & 11 & $32,3 \%$ \\
\hline Mutado & & 7 & $8,6 \%$ & 2 & $6 \%$ \\
\hline Total & & 811 & $100 \%$ & 34 & $100 \%$ \\
\hline Mspl & 0,098 & & & & \\
\hline Selvagem & & 16 & $19,7 \%$ & 3 & $8,8 \%$ \\
\hline Heterozigoto & & 33 & $40,7 \%$ & 21 & $61,8 \%$ \\
\hline Mutado & & 32 & $39,6 \%$ & 10 & $29,4 \%$ \\
\hline Total & & 811 & $100 \%$ & 34 & $100 \%$ \\
\hline
\end{tabular}

*Até $50 \%$ de tecido fibroglandular; ${ }^{\star \star}$ Superior a $50 \%$ de tecido fibroglandular. Haelll (Fisher $=0,712)$. Mspl (Fisher =0,098).

Tabela 5 - Associação entre densidade mamográfica e variáveis clínicas de mulheres $(n=115)$ após a menopausa.

\begin{tabular}{|c|c|c|c|}
\hline \multirow[b]{2}{*}{ Variáveis } & \multicolumn{3}{|c|}{ Densidades } \\
\hline & $\begin{array}{c}\text { Mamas } \\
\text { lipossubstituídas }\end{array}$ & Mamas densas & $p<0,05$ \\
\hline Idade* & 52,5 & 50,4 & 0,02 \\
\hline Menarca* & 13,2 & 13,7 & 0,131 \\
\hline Menopausa* & 48,9 & 47,2 & 0,075 \\
\hline Paridade* & 3 & 2,3 & 0,012 \\
\hline $\mathrm{IMC}^{*}$ & 28,2 & 24,5 & 0,001 \\
\hline Tabagismo** & & & 0,502 \\
\hline $\operatorname{Sim}$ & $19(65,5 \%)$ & $10(34,5 \%)$ & \\
\hline Não & $62(72,1 \%)$ & $24(27,9 \%)$ & \\
\hline Amamentação*** & & & 0,999 \\
\hline Sim & $72(69,9 \%)$ & $31(30,1 \%)$ & \\
\hline Não & $9(75 \%)$ & $3(25 \%)$ & \\
\hline
\end{tabular}

Porém, não houve associação significativa entre densidade mamográfica e as variáveis menarca, menopausa, tabagismo e histórico de amamentação (Tabela 5).

\section{Discussão}

Sendo a densidade mamográfica uma medida do parênquima e estroma, é possivel que mamas mais densas tenham mais risco para câncer mamário por apresentarem maior quantidade de células epiteliais. Além disso, um possível mecanismo relacionando estroma a agressividade tumoral por meio de fatores de crescimento aí produzidos também pode estar associado?

A importância da densidade mamográfica como fator de risco é evidente quando sua magnitude (risco relativo entre 2-6) é comparada com a de outros fatores (como doença proliferativa benigna, história familiar de câncer e alcoolismo), que apresentam risco de $2-4$, e com aqueles que possuem valores $<2$ (como nuliparidade, menarca precoce, menopausa tardia e câncer ginecológico prévio). Embora apresente valores de risco consideráveis, a densidade mamária ainda tem sido pouco valorizada ${ }^{6-8,14}$

Uma outra preocupação, ao se analisar esse tipo de mama, vem da grande dificuldade para detectar tumores em estágio precoce, pois a elevada densidade mamária determina diminuição na sensibilidade mamográfica.

A eficácia da ultra-sonografia para rastrear câncer mamário é questionável, pois não há um valor para redução na mortalidade obtido com esse método. Em um estudo, no qual foram incluídas 3.626 mulheres com mamas densas e avaliadas pela ultra-sonografia, foram encontrados 11 casos de câncer identificados só com esse método, demonstrando uma prevalência de cerca de $0,3 \%{ }^{21}$. Posteriormente, esses mesmos autores demonstraram que a ultra-sonografia associada mamografia apresentava maior sensibilidade para detectar essa doença (97\%) do que mamografia associada a exame clínico $(74 \%)^{22}$.

Os resultados do primeiro estudo para avaliar o desempenho da mamografia digital mostram que esse método parece ser promissor. Em um estudo com 42.760 mulheres observou-se que a acurácia diagnóstica dos dois métodos mamográficos (digital e analógico) era similar para o grupo em geral, mas o desempenho do mamógrafo digital, com relação a detecção de câncer, era significantemente melhor entre mulheres com mamas densas ${ }^{23}$.

Considerando-se que a proliferação celular da mama normal é influenciada pelos hormônios

Rev Bras Ginecol Obstet. 2006; 28(10): 581-89. 
esteróides e que essa ação é mediada por receptores, o conhecimento destes últimos é fundamental para compreender os efeitos hormonais sobre a mama.

Ao analisarem os lóbulos mamários de mulheres antes e após a menopausa, os autores notaram que havia uma diferença na porcentagem de células $\mathrm{RE}+\mathrm{e}$ no índice de proliferação Ki-67. A porcentagem de células $\mathrm{RE}+$ aumenta e a das Ki-67+ diminui com a idade. Ou seja, na mulher após a menopausa haveria maior quantidade de células $\mathrm{RE}+$, porém com índice de proliferação mais baixo ${ }^{24}$.

Erros gênicos podem ser responsáveis pela perda de controle da regulação desses receptores ou da atividade mitogênica, podendo desencadear ou inibir a apoptose. A maior expressão do $\mathrm{RE}$ pode aumentar o índice de proliferação das células epiteliais e ser o responsável pelo padrão mamográfico denso.

A investigação sobre as possíveis associações entre genética, densidade mamária e câncer de mama é um tema promissor. É cada vez mais evidente que os polimorfismos genéticos podem contribuir para o desenvolvimento de doenças em órgãos dependentes de hormônio, como para explicar as variações no padrão mamográfico encontradas na população.

Os polimorfismos em genes que codificam enzimas, receptores ou outras proteínas (que atuam em vias metabólicas potencialmente importantes no câncer de mama) podem influenciar suas funções e criar diferenças na atividade metabólica, capazes de alterar o risco para essa doença. Os candidatos incluem genes para enzimas que metabolizam agentes carcinogênicos, hormônios esteróides, e receptores, como os de estrogênio e progesterona. Acredita-se que qualquer pessoa pode ser heterozigota para alelos que determinam proteínas diferentes, existindo assim um grau marcante de individualidade bioquímica. Variações nos genes codificadores de enzimas importantes (responsáveis pela biossintese estrogênica) resultariam individualmente em diferenças modestas nessa produção. Uma combinação de genes, cada um com menor variação na atividade expressa, proveria um grau de separação de risco que poderia ser usado clinicamente. Essas pequenas variações resultariam em um grande efeito cumulativo após várias décadas ${ }^{9}$.

Os nossos resultados mostram que não houve associação significante entre o polimorfismo HaeIII no gene para o receptor de estrogênio alfa com mama densa. Esses dados são concordantes com os de outros estudos, que também tentaram encontrar uma causa genética determinante do padrão mamográfico ${ }^{12,13}$.

No entanto, o polimorfismo MspI mostrou uma associação mais próxima do significado estatístico. Acreditamos que essa relação não atingiu um grau de significância devido ao número reduzido de pacientes com mamas extremamente densas. Notamos que não houve grande diferença entre o número de mulheres com esse tipo de mama, conforme determinado pelos três observadores. Além disso, embora esse número tenha sido pequeno, o grau de associação com tendência a significância estava presente. Isso nos faz supor que realmente pode existir uma associação entre o polimorfismo $M s p I$ e padrão mamográfico de densidade elevada.

O polimorfismo MspI do gene para o receptor de estrogênio alfa pode ser responsável por uma exacerbação na função do receptor, determinando maior proliferação epitelial, que pode se traduzir radiologicamente em mama densa.

Dos fatores clínicos estudados, sabemos que o aumento no peso provoca diminuição na densidade mamográfica. Notamos que as pacientes com média de IMC $=28,29$ tinham mamas mais lipossubstituídas do que aquelas com média de IMC $=24,57$. Essa diferença foi significante, o que também foi referido por outros autores ${ }^{25}$.

Em relação à idade, observamos que quanto mais jovem é a mulher, maior é a quantidade de tecido fibroglandular e menor a de tecido gorduroso. Verificamos que o grupo de pacientes com média de idade $=52,5$ anos tinha densidade mamária menor que a do grupo com média de idade $=50,4$ anos. Essa associação foi considerada significante. Este fato também foi observado por outros autores ${ }^{14,16,26}$.

Uma menarca precoce pode estar associada a um início mais rápido nos ciclos ovulatórios e, por isso, a uma exposição vitalícia maior aos hormônios endógenos, a qual pode provocar maior proliferação epitelial ${ }^{25}$. Não encontramos associação significativa entre idade da menarca e densidade mamográfica aumentada. Notamos que as médias de idade eram muito semelhantes (13,2 e 13,7 anos) nos dois grupos de densidades estudadas (mamas lipossubstituídas e mamas densas, respectivamente).

A maioria das mulheres (81-70,4\%) tinha mamas lipossubstituídas (provavelmente devido a cessação na divisão celular mamária), com interrupção dos niveis de hormônios endógenos, o que está de acordo com a literatura $^{14,16,25,26}$. Encontramos associação próxima da significância estatística entre menopausa e densidade mamográfica. 
Com as gestações sucessivas, as células epiteliais encontram-se mais diferenciadas e menos proliferativas, o que pode se traduzir radiologicamente em uma densidade mamográfica menor. Verificamos que as mulheres com média de paridade $=3,0$ (81 pacientes) tinham mamas mais lipossubstituídas do que aquelas com média de paridade $=2,3$ (34 pacientes). Essa relação entre paridade e densidade mamográfica se mostrou estatisticamente significante $(\mathrm{p}=0,012)$.

Fato semelhante também foi encontrado por Gram et al. ${ }^{2}$. A proporção de padrão mamográfico com alto risco para câncer diminuía com o aumento na paridade. Cerca de $90 \%$ das mulheres com mais de 4 filhos tinham mamas com padrão de baixo risco. Quando os critérios de Wolfe ${ }^{1}$ eram usados para classificar essas pacientes, notava-se comportamento semelhante, porém com valor percentual menor.

Observa-se que as taxas para câncer de mama são mais baixas em populações em que a amamentação é prolongada e comum. Infelizmente, normas sociais na nossa cultura, relacionadas com paridade e amamentação, limitam o estudo desse fator preventivo potencial. Ao avaliar uma possivel associação entre densidade mamográfica e período de amamentação de até 6 meses, não evidenciamos uma relação significante.

A relação entre fumante ativa e risco para câncer de mama também tem sido avaliada. Os dados fornecem evidência contra qualquer relação maior. Embora haja relatos de que o uso do cigarro no início da adolescência (quando o tecido mamário seria mais sensivel a influências carcinogênicas) estava associado a um risco aumentado para câncer de mama, não havia referências sobre associação com densidade mamária ${ }^{27}$. Não encontramos uma relação estatística entre densidade mamográfica e tabagismo $(\mathrm{p}=0,502)$.

O padrão mamográfico é multifatorial. Idade, história reprodutiva, situação hormonal, constituição corporal e fatores genéticos podem estar envolvidos, determinando a densidade mamária. Os estudos da influência genética sobre o padrão mamográfico estão se iniciando. Encontrar um "fator intrínseco" responsável pela mama densa em mulheres após a menopausa é um tema promissor, principalmente porque esse mesmo fator poderia ser considerado um fator de risco para câncer de mama.

\section{Referências}

1. Wolfe JN. Breast patterns as an index of risk for developing breast cancer. AJR Am J Roentgenol. 1976;126(6):1130-7.
2. Gram IT, Funkhouser E, Tabár L. The Tabár classification of mammographic parenchymal patterns. Eur J Radiol. 1997;24(2):131-6.

3. Breast Imaging Reporting and Data System $\left(B I-R A D S^{\circledR}\right)$. Mammography. 4th ed. Reston: American College of Radiology; 2003.

4. Kopans DB. Imagem da mama. $2^{a}$ ed. Rio de Janeiro: MEDSI; 2000. p. 229-46.

5. Boyd NF, Lockwood GA, Martin LJ, Knigth JA, Byng JW, Yaffe MJ, et al. Mammographic densities and breast cancer risk. Breast Dis. 1998;10(3-4): 113-26.

6. Warner E, Lockwood G, Tritchler D, Boyd NF. The risk of breast cancer associated with mammographic parenchymal patterns: a meta-analysis of the published literature to examine the affect of method of classification. Cancer Detect Prev. 1992;16(1):67-72.

7. Mandelson MT, Oestreicher N, Porter PL, White D, Finder CA, Taplin SH, et al. Breast density as a predictor of mammographic detection: comparison of interval-and screen-detected cancers. J Natl Cancer Inst. 2000;92(13):1081-7.

8. Michaelson J, Satija S, Moore R, Weber G, Halpern $\mathrm{E}$, Garland A, et al. The pattern of breast cancer screening utilization and its consequences. Cancer. 2002;94(1):37-43.

9. Feigelson HS, Henderson BE. Future possibilities in the prevention of breast cancer: role of genetic variation in breast cancer prevention. Breast Cancer Res. 2000;2(4):277-82.

10.Nussbaum RL, McInnes RR, Willard HF. Thompson \& Thompson: genética médica. $6^{\mathrm{a}}$ ed. Rio de Janeiro: Guanabara Koogan; 2002. p. 69-82.

11.Cai Q, Shu XO, Jin F, Dai Q, Wen W, Cheng JR, et al. Genetic polymorphisms in the estrogen receptor a gene and risk of breast cancer: results from the Shangai Breast Cancer Study. Cancer Epidemiol Biomarkers Prev. 2003;12(9):853-9.

12.Haiman CA, Hankinson SE, De Vivo I, Guillemette C, Ishibe $\mathrm{N}$, Hunter DJ, et al. Polymorphisms in steroid hormone pathway genes and mammographic density. Breast Cancer Res Treat. 2003;77(1):27-36.

13.Pankow JS, Vachon CM, Kuni CC, King RA, Arnett DK, Grabrick DM, et al. Genetic analysis of mammographic breast density in adult women: evidence of a gene effect. J Natl Cancer Inst. 1997;89(8): 549-56.

14. Haiman CA, Bernstein L, Berg D, Ingles SA, Salane M, Ursin G: Genetic determinants of mammographic density. Breast Cancer Res. 2002;4(3):R5.

15.van Duijnhoven FJ, Bezemer ID, Peeters PH, Roest M, Uitterlinden AG, Grobbee DE, et al. Polymorphisms in the estrogen receptor alpha gene and mammographic density. Cancer Epidemiol Biomarkers Prev. 2005;14 (11 Pt 1): 2655-60.

Rev Bras Ginecol Obstet. 2006; 28(10): 581-89. 
16.Ziv E, Shepherd J, Smith-Bindman R, Kerlikowske K. Mammographic breast density and family history of breast cancer. J Natl Cancer Inst. 2003;95(7):556-8.

17.Lai JH, Vesprini D, Zhang W, Yaffe MJ, Pollak M, Narod SA. A polymorphic locus in the promoter region of the IGFBP-3 gene is related to mammographic breast density. Cancer Epidemiol Biomarkers Prev. 2004;13(4):573-82.

18.van Duijnhoven FJ, Peeters PH, Warren RM, Bingham SA, Uitterlinden AG, van Noord PA, et al. Influence of estrogen receptor alpha and progesterone receptor polymorphisms on the effects of hormone therapy on mammographic density. Cancer Epidemiol Biomarkers Prev. 2006;15(3):462-7.

19. Gresti A. Categorical data analysis. $2^{\text {nd }}$ ed. New York: John Wiley and Sons; 2002.

20.Neter J, Wasserman W, Kutner MH. Applied linear statistical models. 3rd ed. New York: Irwin; 1990.

21.Kolb TM, Lichy J, Newhouse JH. Occult cancer in women with dense breasts: detection with screening US - diagnostic yield and tumor characteristics. Radiology. 1998;207(1):191-9.

22.Kolb TM, Lichy J, Newhouse JH. Comparison of the performance of screening mammography, physical examination, and breast US and evaluation of factors that influence them: an analysis of 27,825 patient evaluations. Radiology. 2002;225(1):165-75.

23.Pisano ED, Gatsonis C, Hendrick E, Yaffe M, Baum JK, Acharyya S, et al. Diagnostic performance of digital versus film mammography for breast cancer screening. N Engl J Med. 2005;353(17):1773-83.

24.Shoker BS, Jarvis C, Clarke RB, Anderson E, Hewlett J, Davies MP, et al. Estrogen receptor-positive proliferating cells in the normal and precancerous breast. Am J Pathol. 1999;155(6):1811-5.

25. Siqueira RFCB, Sá DSB, Pinto Neto AM, Cabello C, Conde DM, Paiva LHSC, et al. Fatores associados à densidade mamográfica de mulheres na pósmenopausa. Rev Bras Ginecol Obstet. 2004;26(1): 45-52.

26. Stomper PC, D'Souza DJ, DiNitto PA, Arredondo MA. Analysis of parenchymal density on mammograms in 1353 women 25-79 years old. AJR Am J Roentgenol. 1996;167(5):1261-5.

27.Baron JA, Newcomb PA, Longnecker MP, Mittendorf R, Storer BE, Clapp RW. Cigarrette smoking and breast cancer. Cancer Epidemiol Biom Prev. 1996;5(5): 399-403. 